\title{
Effects of Aluminium Addition on the Oxide Film Formed on 304 Stainless Steel in the Simulated Primary Circuit of the PWR
}

\author{
Shenghan Zhang, Xiaofang Song ${ }^{*}$, Kegang Zhang, Qingxiao Hua, Yu Tan \\ School of Environmental Science \& Engineering, North China Electric Power University, Baoding \\ 071003, Hebei Province, P. R. China \\ *E-mail: wantong1998@163.com
}

doi: $10.20964 / 2017.12 .01$

Received: 6 June 2017 / Accepted: 18 September 2017 / Published: 12 November 2017

\begin{abstract}
Aluminium $\left(\mathrm{Al}^{3+}\right)$ addition in the simulated primary circuit of the pressurized water reactor (PWR) was investigated based on its effect on the oxide film formed on 304 stainless steel (SS). SEM images showed the formation of more compact oxide films after $\mathrm{Al}^{3+}$ addition. Deposition of cobalt was inhibited by $\mathrm{Al}^{3+}$ addition according to the results from EDX and XPS. Potentiodynamic polarization analysis demonstrated that the corrosion potential of the oxide films observably increased and that the corrosion current density remarkably decreased after $\mathrm{Al}^{3+}$ addition. Mott-Schottky plots showed that the semiconductor properties of the oxide films could be changed by $\mathrm{Al}^{3+}$ addition. These results revealed the composition and structure changes of the oxide films that resulted in corrosion inhibition of $304 \mathrm{SS}$ and prevention of the radiation field build-up of $\mathrm{Co}^{2+}$ in the simulated primary circuit of the PWR. The current work offers a good solution for corrosion and radiation build-up of structural materials in many nuclear plants.
\end{abstract}

Keywords: Aluminium addition, 304 Stainless steel, Pressurized water reactor, Oxide film.

\section{FULL TEXT}

(C) 2017 The Authors. Published by ESG (www.electrochemsci.org). This article is an open access article distributed under the terms and conditions of the Creative Commons Attribution license (http://creativecommons.org/licenses/by/4.0/). 